\title{
Studi Susut Energi Pada Penyulang Perunggu Gardu Induk Sutami
}

\author{
Hanif Fauji'; Samsurizal ${ }^{2}$ \\ 1,2 Teknik Elektro (Institut Teknologi PLN) \\ ${ }^{2}$ samsurizal@itpln.ac.id
}

\begin{abstract}
Power shrinking events in the distribution network are unavoidable events, but the amount of power shrinking that occurs can still be overcome or suppressed to a minimum for that is the need to prevent the onsanion of large amounts of shrinking by means of maintenance and repair of distribution system equipment, the calculation of power shrink is carried out by quantitative method where the data retrieved is the peak current time data. From the results of the study conducted in The Bronze Purgator obtained a daily average shrinkage value of $5.37 \%$, and the calculation result was obtained that the average energy shrinkage that occurred within a month was $3981,717 \mathrm{kWh}$.
\end{abstract}

Keywords: Losses Energy, Bribery, Distribution

\begin{abstract}
ABSTRAK
Peristiwa susut daya pada jaringan distribusi ialah peristiwa yang tidak dapat dihindari, namun besarnya susut daya yang terjadi masih bisa diatasi atau ditekan seminimal mungkin untuk itu perlunya melakukan pencegahan terjadinya susut dalam jumlah besar dengan cara perawatan dan perbaikan peralatan sistem distribusi, perhitungan susut daya dilaksanakan dengan metode kuantitatif dimana data yang diambil adalah data waktu arus puncak. Dari hasil studi yang dilakukan pada Penyulang Perunggu didapatkan nilai susut rata rata harian sebesar $5,37 \%$, dan hasil perhitungan didapatkan bahwa besarnya susut energi rata rata yang terjadi dalam waktu satu bulan adalah $3981,717 \mathrm{kWh}$.
\end{abstract}

Kata Kunci: Susut Energi, Penyulang, Distribusi 


\section{PENDAHULUAN}

Pada penyaluran energi listrik bagian yang terdekat dengan konsumenatau masyarakat adalah sistem distribusi, sistem distribusi merupakan tahap akhir dalam pengiriman tenaga listrik yang menyalurkan energi listrik dari sisi trafo sekunder pada gardu induk sampai dengan penyaluran kepada setiap konsumen namun dalam penyalurannya daya listrik tidak seluruhnya dapat diterima oleh konsumen karena akan adanya daya yang hilang pada proses penyaluran itu dalam bentuk susut daya[1].

Susut (losses) merupakan banyaknya energi yang hilang dalam proses pengaliran energi listrik mulai dari gardu induk sampai dengan konsumen, susut sendiri adalah kejadian atau gangguan yang tidak dapat dihindari dari jaringan distribusi, apabila tidak ada gardu induk susut (losses) dimulai dari gardu distribusi sampai dengan konsumen[2][3], Menurut keputusan Direksti PT. PLN (Persero) No. 217-1.K/DIR/205 tentang pedoman penyusutan neraca Energi $(\mathrm{kWh})$, susut pada saluran distribusi perlu diperhatikan karena besarnya susut lebih banyak terjadi pada sistem distribusi, hilangnya energi ini perlu di diperkiraan dan di Analisa agar tidak melebihi dari pada standar yang telah ditentukan, dan menyebabkan kerugian yang cukup besar, kurangnya pasokan listrik pada suatu daerah akan mempengaruhi kualitas listrik itu sendiri dan dapat berakibat tegangan rendah bahkan pemadaman listrik secara bergilir[4][5].

Lampung merupakan salah Satu Daerah yang sistem pendistribusian pada penyulang masih menggunakan panjang penyulang yang jukup panjang,panjang nya jaringan mempengaruhi terjadinya susut karena semakin panjang jaringan maka semakin besar pula hambatan yang dihasilkan, analisa perhitungan susut energy akan dilakukan pada penyulang perunggu,penyulang perunggu adalah salah satu penyulang yang cukup panjang dan memiliki arus beban cukup besar yang berada di gardu induk sutami, metode pengambilan data yang dilakukan adalah studi pustaka, wawancara dan juga pengambilan data di PLN UP2D Lampung kemudian dilakukannya perhitungan untuk mendapatkan hasil susut yang terjadi pada penyulang perunggu.

\section{METODE PENELITIAN}

Dalam Pelaksanaan Penelitian ini, Peneliti menggunakan beberapa tahapan atau metode untuk menyelesaikan penelitian Berikut ini adalah diagram alur dari proses ditunjukkan gambar 1 . 


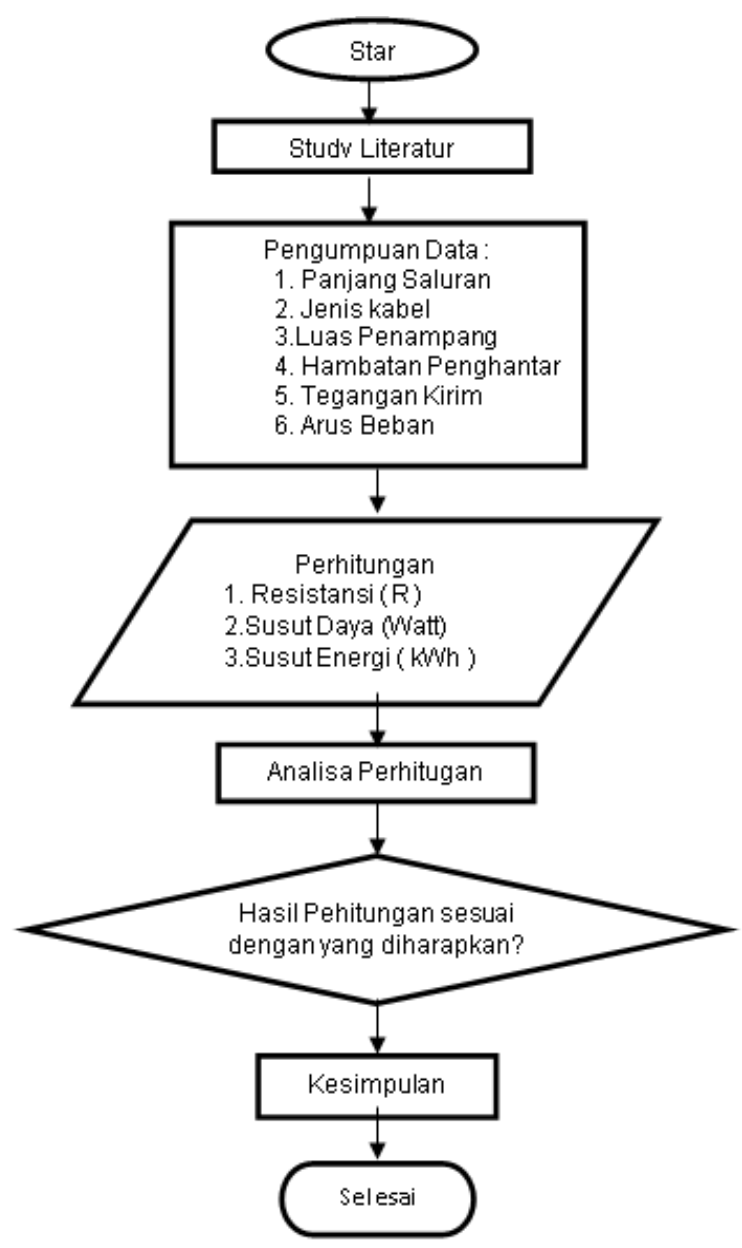

Gambar 1. Flowchart Rancangan Penelitian

Pada penelitian ini digunakan metode Statis Deskriptif yaitu denganTeknik analisis yang dilakukan dengan cara mendeskripsikan atau menggambarkan data yang telah terkumpul,dalam penelitan ini didapatkan data data teknis dari penyulang, data yang telah didapat kemudian diolah dengan melakukan perhitungan perhitungan dengan rumus yang ada, seperti melakukan perhitungan resistansi, susut daya dan susut energi, kemudain melakukan peninjauan apakah perhitungan yang telah dilaksanakan sesuai dengan stardar yang telah ada, dan memberikan kesimpulan dan juga analisis atas apa yang telah dikerjakan.

Persamaan daya aktif $(\mathrm{P})$ pada beban persamaan :

$$
\text { P3fasa }=\sqrt{3} x \text { V x I } x \operatorname{Cos} \theta
$$

Dimana:

$$
\begin{array}{ll}
\mathrm{P} & =\text { Daya Aktif }(\mathrm{W}) \\
\mathrm{V} & =\text { Tegangan }(\mathrm{V}) \\
\mathrm{I} & =\text { Arus Listrik }(\mathrm{A}) \\
\operatorname{Cos} \theta & =\text { Faktor Daya }
\end{array}
$$


Resistansi listrik adalah hambatan yang terjadi pada aliran arus listrik untuk menghitung nilai resistansi digunakan suhu 600 yang dimaksudkan sebagai suhu beban puncak, sesuai dengan standar SPLN 87 - 1991. Resistansi Penghantar dapat dihitunh dengan menggunakan persamaan berikut :

$$
\frac{R 2}{R 1}=\frac{T o+60^{\circ}}{T o+20^{\circ}}
$$

Dimana:

$$
\begin{aligned}
& \mathrm{R} 2=\text { nilai resistansi konduktor bekerja }(\Omega / \mathrm{km}) \\
& \mathrm{R} 1=\text { nilai Resistansi konduktor normal }(\Omega / \mathrm{km}) \\
& \mathrm{To}=\text { temperatur transisi (alumunium }=228)
\end{aligned}
$$

\section{HASIL DAN PEMBAHASAN}

Pada bab ini akan membahas perhitungan susut daya dan susut energi saluran udara dan kabel pada penyulang perunggu gardu induk Sutami, untuk mendapat nilai susut daya dan susut energy pada penyulang perunggu dibutuhkan beberapa data, data yang diperulkan dalam perhittungan ini antara lain yaitu data jenis konduktor, panjang konduktor dan beban puncak di beberapa waktu.

\subsection{Data Konduktor}

Pada Penyulang Perunggu digunakan dua jenis kawat penghantar dengan diameter $150 \mathrm{~mm}^{2}$ dengan data yang dita,pilkan pada tabel 1 .

Tabel 1. Data Konduktor

\begin{tabular}{|c|c|c|c|}
\hline Tipe & $\begin{array}{c}\text { Luas } \\
\text { Penampang } \\
\mathrm{mm}^{2}\end{array}$ & $\begin{array}{c}\text { Resistansi (Ohm } \\
/ \mathrm{KM})\end{array}$ & $\begin{array}{c}\text { Panjang } \\
\text { Penghantar } \\
(\mathrm{KM})\end{array}$ \\
\hline $\begin{array}{c}\text { AAAC } \\
\text { (All Alumunium Concuctor) }\end{array}$ & 150 & 0,210 & 19,74 \\
\hline A2XSEYBY & 150 & 0,206 & 1,93 \\
\hline
\end{tabular}

Sumber : SPLN 43-5-4 :1995 dan SPLN 41-8-1981

\subsection{Data Beban Penyulang Perunggu Pada Bulan Januari 2020}

Untuk mendapatkan nilai daya aktif yang digunakan pada penyulang Perunggu maka digunakan persamaan untuk mendapatkan nilai dari pada besarnya daya atau Beban Puncak maka digunakan persamaan 1. Setelah dilakukan perhitungan dengan menggunakan persamaan tersebut dengan menggunakan data tegangan kirim dan arus beban yang telah di dapat kan maka hasil ditunjukkan pada tabel 2.

Tabel 2. Data Penyulang Perunggu

\begin{tabular}{|c|c|c|c|c|c|c|}
\hline \multirow{2}{*}{ Tanggal } & \multicolumn{2}{|c|}{ Tegangan Kirim (Kv) } & \multicolumn{2}{c|}{ Arus (A) } & \multicolumn{2}{c|}{ Daya (MW) } \\
\cline { 2 - 7 } & Pukul & Pukul & Pukul & Pukul & Pukul & Pukul \\
& 07.00 & 19.00 & 07.00 & 19.00 & 07.00 & 19.00 \\
\hline 1 & 20,8 & 21 & 63 & 90 & 1,93 & 2,78 \\
\hline 2 & 20,7 & 21 & 85 & 112 & 2,59 & 3,46 \\
\hline 3 & 20,8 & 21,2 & 106 & 110 & 3,24 & 3,43 \\
\hline 4 & 20,7 & 21 & 110 & 110 & 3,35 & 3,40 \\
\hline
\end{tabular}




\begin{tabular}{|c|c|c|c|c|c|c|}
\hline 5 & 20,7 & 21 & 85 & 110 & 2,59 & 3,40 \\
\hline 6 & 20,9 & 21 & 106 & 128 & 3,26 & 3,96 \\
\hline 7 & 21 & 20,9 & 79 & 121 & 2,44 & 3,72 \\
\hline 8 & 20,8 & 21,2 & 108 & 107 & 3,31 & 3,24 \\
\hline 9 & 20,7 & 21 & 80 & 129 & 2,44 & 3,99 \\
\hline 10 & 21 & 21,1 & 100 & 112 & 3,12 & 3,79 \\
\hline 11 & 21,2 & 21 & 106 & 112 & 3,30 & 3,46 \\
\hline 12 & 20,8 & 21,2 & 108 & 107 & 3,31 & 3,24 \\
\hline 13 & 20,9 & 21 & 104 & 109 & 3,19 & 3,37 \\
\hline 14 & 21 & 21,1 & 87 & 120 & 2,69 & 3,37 \\
\hline 15 & 20,6 & 21,2 & 80 & 131 & 2,43 & 4,09 \\
\hline 16 & 21 & 21 & 106 & 130 & 3,28 & 4,02 \\
\hline 17 & 20,6 & 21 & 80 & 98 & 2,43 & 3,03 \\
\hline 18 & 20,9 & 21,1 & 88 & 98 & 2,71 & 3,03 \\
\hline 19 & 21.1 & 21,05 & 96 & 106 & 2,98 & 3,28 \\
\hline 20 & 21.1 & 21 & 82 & 125 & 2,55 & 3,86 \\
\hline 21 & 20.9 & 21 & 99 & 128 & 3,05 & 3,96 \\
\hline 22 & 21 & 20,9 & 102 & 104 & 3,15 & 3,20 \\
\hline 23 & 20,8 & 21 & 89 & 110 & 2,73 & 3,40 \\
\hline 24 & 20,9 & 21 & 85 & 112 & 2,62 & 3,46 \\
\hline 25 & 21 & 21,03 & 71 & 105 & 2,20 & 3,25 \\
\hline 26 & 21 & 21 & 71 & 101 & 2,20 & 3,12 \\
\hline 27 & 21,2 & 21 & 80 & 109 & 2,50 & 3,37 \\
\hline 28 & 21 & 20,9 & 82 & 123 & 2,54 & 3,78 \\
\hline 29 & 21 & 21 & 76 & 131 & 2,35 & 4,05 \\
\hline 30 & 21 & 21 & 76 & 109 & 2,35 & 3,37 \\
\hline 31 & 21 & 20,9 & 90 & 91 & 3,09 & 2,8 \\
\hline & & & & & & \\
\hline
\end{tabular}

\subsection{Perhitungan nilai Resistansi}

Untuk melakukan perhitungan Resistansi maka digunakan persamaan beberapa persamaan Nilai Resistansi (R) pada sebuah konduktor adalah nilai disetiap 1 kilometer, pada perhitungan ini digunakan perhitungan dengan suhu $60^{\circ}$ yang di asumsikan sebagai suhu penghantar pada keadan beban puncak sehingga resistansi total penghantar pada Penyulang perunggu denggan Panjang Penyulang 21,67 KM adalah :

Perhitungan Resistansi Pada AAAC

R2 $228+60^{\circ}$

$\frac{R 1}{R 1}=\frac{228+60^{\circ}}{228+20^{\circ}}$

$248 \mathrm{R}_{2}=288 \times(0,210)$

$\mathrm{R}_{2}=0,24837 \Omega / \mathrm{Km} \times 1,02$ (faktor koreksi)

$\mathrm{R}_{2}=0,2487$

$R=0,2487 \times 19,74=4,90 \Omega$
Perhitungan Resistansi Pada NA2XSEYBY

$\frac{R 2}{R 1}=\frac{228+60^{\circ}}{228+20^{\circ}}$

$\overline{R 1}=\frac{228+60^{\circ}}{228+280^{\circ}}$

$248 \mathrm{R}_{2}=288 \times(0,206)$

$\mathrm{R}_{2}=0,2392 \Omega / \mathrm{Km} \times 1,02$ (faktor koreksi)

$\mathrm{R}_{2}=0,244 \Omega / \mathrm{Km}$

$\mathrm{R}=0,244 \times 1,93 \mathrm{Km}=0,47 \Omega$

\subsection{Perhitungan Rugi-Rugi Daya Penghantar}

Untuk mendapatkan nilai susut pada penghatar maka dapat dignakan persamaan $\left(\mathrm{I}^{2} \mathrm{R}\right)$ dan menggunakan nilai resistansi pada penghantar yang telah didapatkan pada perhitungan sebelumnya: 
Vol. 10, No. 1, Juni 2020, P-ISSN 2356-1505, E-ISSN 2656-9175

https://doi.org/10.33322/sutet.v10i1.1138

Pada AAAC di pukul 07.00

01 Januari 2020

Plosses

$$
\begin{aligned}
& =3 \cdot I^{2} \cdot R \\
& =3 \times(63 \mathrm{~A})^{2} \times 4,9 \Omega \\
& =58 \cdot 344 \mathrm{~W} \\
& =58,34 \mathrm{~kW}
\end{aligned}
$$

Pada AAAC di pukul 19.00 01 Januari 2020

Plosses $\quad=3.1^{2} \cdot R$

$$
\begin{aligned}
& =3 \times(90 \mathrm{~A})^{2} \times 4,9 \Omega \\
& =119.072 \mathrm{~W} \\
& =119,07 \mathrm{~kW}
\end{aligned}
$$

Pada NA2XSEYBY Pukul 07.00 01 Januari 2020

Plosses $\quad=3 \cdot \mathrm{I}^{2} \cdot \mathrm{R}$

$$
\begin{aligned}
& =3 \times(63 \mathrm{~A})^{2} \times 0,47 \Omega \\
& =5596 \mathrm{~W} \\
& =5,59 \mathrm{~kW}
\end{aligned}
$$

\begin{tabular}{|c|c|c|c|c|c|c|}
\hline \multirow{2}{*}{ Tanggal } & \multicolumn{2}{|c|}{ Susut Pada Siang hari } & \multicolumn{2}{|c|}{$\begin{array}{l}\text { Susut Pada Malam } \\
\text { hari }\end{array}$} & \multicolumn{2}{|c|}{ Total Susut } \\
\hline & AAAC (MV) & $\begin{array}{l}\text { NA2XSEYBY } \\
\text { (MV) }\end{array}$ & $\begin{array}{l}\text { AAAC } \\
\text { (MV) }\end{array}$ & $\begin{array}{l}\text { NA2XSEYBY } \\
\text { (MW) }\end{array}$ & $\begin{array}{c}\text { Siang } \\
\text { Hari }\end{array}$ & $\begin{array}{c}\text { Malam } \\
\text { Hari }\end{array}$ \\
\hline 1 & 58,34 & 5,59 & 119,07 & 11,42 & 63,93 & 130,49 \\
\hline 2 & 106,20 & 10,18 & 184,39 & 17,68 & 116,38 & 202,07 \\
\hline 3 & 165,16 & 15,84 & 177,87 & 17,06 & 181 & 194,93 \\
\hline 4 & 177,87 & 17,06 & 177,87 & 17,06 & 194,93 & 194,93 \\
\hline 5 & 106,20 & 10,18 & 177,87 & 17,06 & 116,38 & 194,93 \\
\hline 6 & 165,16 & 15,84 & 240,84 & 23,10 & 181 & 263,94 \\
\hline 7 & 91,74 & 8,79 & 215,22 & 20,64 & 100,53 & 235,86 \\
\hline 8 & 171,46 & 16,44 & 168,30 & 16,14 & 187,9 & 184,44 \\
\hline 9 & 94,08 & 9,02 & 244,62 & 23,46 & 103,1 & 268,08 \\
\hline 10 & 147 & 14,1 & 184,39 & 17,68 & 161,1 & 202,07 \\
\hline 11 & 165,16 & 15,84 & 184,39 & 17,68 & 181 & 202,07 \\
\hline 12 & 171,46 & 16,44 & 168,30 & 16,14 & 187,9 & 184,44 \\
\hline 13 & 158,99 & 15,25 & 174,65 & 16,75 & 174,24 & 191,4 \\
\hline 14 & 111,26 & 10,67 & 211,68 & 20,30 & 121,93 & 231,98 \\
\hline 15 & 94,08 & 9,02 & 252,26 & 24,19 & 103,1 & 276,45 \\
\hline 16 & 165,16 & 15,84 & 248,43 & 23,82 & 181 & 272,25 \\
\hline 17 & 94,08 & 9,02 & 141,17 & 13,54 & 103,1 & 154,71 \\
\hline 18 & 113,83 & 10,91 & 141,17 & 13,54 & 124,74 & 154,71 \\
\hline 19 & 135,47 & 12,99 & 165,16 & 15,84 & 148,46 & 181 \\
\hline 20 & 98,84 & 9,48 & 229,68 & 22,03 & 108,32 & 251,71 \\
\hline 21 & 144,07 & 13,81 & 240,84 & 23,10 & 157,88 & 263,94 \\
\hline 22 & 152,93 & 14,66 & 158,99 & 15,25 & 167,59 & 174,24 \\
\hline 23 & 116,43 & 11,16 & 177,87 & 17,06 & 127,59 & 194,93 \\
\hline 24 & 106,20 & 10,18 & 184,39 & 17,68 & 116,38 & 202,07 \\
\hline 25 & 74,10 & 7,10 & 162,06 & 15,54 & 81,2 & 177,6 \\
\hline
\end{tabular}

Pada NA2XSEYBY Pukul 19.00 01 Januari 2020

Plosses

$$
\begin{aligned}
& =3 \cdot I^{2} \cdot R \\
& =3 \times(90 A)^{2} \times 0,3975 \Omega \\
& =11421 \mathrm{~W} \\
& =11,42 \mathrm{~kW}
\end{aligned}
$$

Dari hasil Perhitungan yang telah dilakukan maka didapatkan nilai susut pada penghantar yang hasilnya ditampilkan pada tabel 3. sebagai berikut :

Tabel 3. Hasil Perhitungan Rugi-Rugi Daya Penghantar 


\begin{tabular}{|c|c|c|c|c|c|c|}
\hline 26 & 74,10 & 7,10 & 149,95 & 14,38 & 81,2 & 164,33 \\
\hline 27 & 94,08 & 9,02 & 174,65 & 16,75 & 103,1 & 191,4 \\
\hline 28 & 98,84 & 9,48 & 222,39 & 21,33 & 108,32 & 243,72 \\
\hline 29 & 84,90 & 8,14 & 252,26 & 24,19 & 93,04 & 276,45 \\
\hline 30 & 84,90 & 8,14 & 174,65 & 16,75 & 93,04 & 191,4 \\
\hline 31 & 119,07 & 11,4 & 121,73 & 11,67 & 130,4 & 133,4 \\
\hline
\end{tabular}

Untuk mempermudah pembacaan tabel dan dapat mengetahui langsung dari pada susut yang terjadi maka dapat dilihat pada gambar 2.2 yaitu gambar grafik susut daya penyulang Perunggu januari 2020.

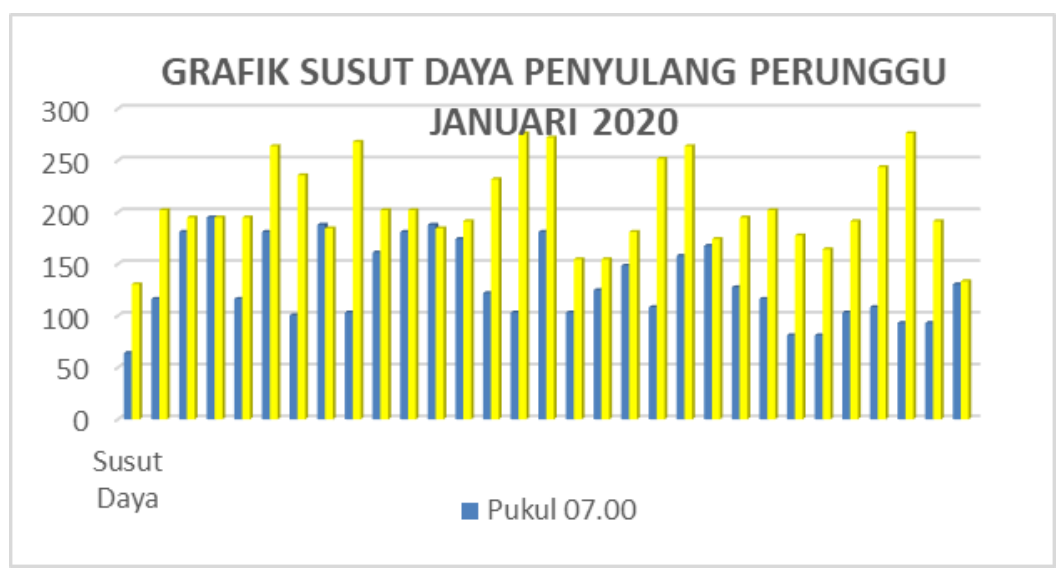

Gambar 2. Grafik susut daya penyulang perunggu Januari 2020

Dari Gambar 2. Grafik susut daya penyulang perunggu Januari 2020 dapat kita ketahui arus beban pada malam hari lebih tinggi dari pada arus beban pada siang hari dari data tersebut dapat kita ketahui bahwa pelanggan penyulang penggu didominasi oleh pelanggan rumah tangga yang nilai arus bebannya lebih tinggi saaat malam hari.

\subsection{Perhitungan Susut Energi Penyulang Perunggu}

Untuk melakukan perhitungan susut Energi pada penyulang Perunggu maka diperlukan nilai daya rata rata harian dan nilai rata rata susut harian, perhitungan dapat dilakukan dengan perhitungan disajikan pada tabel 4 .

Tabel 4. Hasil perhitungan susut energi penyulang perunggu

\begin{tabular}{|c|c|c|c|c|}
\hline Tanggal & $\begin{array}{c}\text { Rata Rata } \\
\text { Daya Harian } \\
(\mathrm{KW})\end{array}$ & $\begin{array}{c}\text { Rata Rata } \\
\text { Susut Harian } \\
(\mathrm{KW})\end{array}$ & $\begin{array}{c}\text { Presentase } \\
\text { Susut Harian }\end{array}$ & $\begin{array}{c}\text { Susut Energi } \\
(\mathrm{kWh})\end{array}$ \\
\hline 1 & 2,35 & 97,21 & $4,13 \%$ & 2333,04 \\
\hline 2 & 3,52 & 159,22 & $4,52 \%$ & 3821,28 \\
\hline 3 & 3,02 & 187,96 & $6,22 \%$ & 4511,04 \\
\hline 4 & 3,37 & 194,93 & $5,78 \%$ & 4678,32 \\
\hline 5 & 2,99 & 155,65 & $5,20 \%$ & 3735,6 \\
\hline 6 & 3,61 & 222,47 & $6,16 \%$ & 5339,28 \\
\hline 7 & 3,08 & 168,19 & $5,46 \%$ & 4036,56 \\
\hline 8 & 3,27 & 186,17 & $5,69 \%$ & 4468,08 \\
\hline
\end{tabular}




\begin{tabular}{|c|c|c|c|c|}
\hline 9 & 3,21 & 185,59 & $5,78 \%$ & 4454,16 \\
\hline 10 & 3,45 & 181,58 & $5,26 \%$ & 4357,92 \\
\hline 11 & 3,38 & 191,53 & $5,66 \%$ & 4596,72 \\
\hline 12 & 3,27 & 186,17 & $5,69 \%$ & 4468,08 \\
\hline 13 & 3,28 & 182,82 & $5,57 \%$ & 4387,68 \\
\hline 14 & 3,03 & 176,95 & $5,83 \%$ & 4246,8 \\
\hline 15 & 3,26 & 189,77 & $5,82 \%$ & 4554,48 \\
\hline 16 & 3,65 & 226,62 & $6,20 \%$ & 5438,88 \\
\hline 17 & 2,73 & 128,90 & $4,72 \%$ & 3093,6 \\
\hline 18 & 2,87 & 139,72 & $4,86 \%$ & 3353,28 \\
\hline 19 & 3,13 & 164,73 & $5,26 \%$ & 3953,52 \\
\hline 20 & 3,2 & 180,01 & $5,62 \%$ & 4320,24 \\
\hline 21 & 3,5 & 210,91 & $6,02 \%$ & 5061,84 \\
\hline 22 & 3,17 & 170,91 & $5,39 \%$ & 4101,84 \\
\hline 23 & 3,06 & 161,26 & $5,26 \%$ & 3870,24 \\
\hline 24 & 3,04 & 159,22 & $5,23 \%$ & 3821,28 \\
\hline 25 & 2,72 & 129,4 & $4,75 \%$ & 3105,6 \\
\hline 26 & 2,66 & 122,76 & $4,61 \%$ & 2946,24 \\
\hline 27 & 2,93 & 147,25 & $5,02 \%$ & 3534 \\
\hline 28 & 3,16 & 176,02 & $5,57 \%$ & 4224,48 \\
\hline 29 & 3,2 & 184,74 & $5,77 \%$ & 4433,76 \\
\hline 30 & 2,86 & 142,22 & $4,97 \%$ & 3413,28 \\
\hline 31 & 2,94 & 131,9 & $4,48 \%$ & 3165,6 \\
\hline Jumlah & - & - & - & 125826,7 \\
\hline Rata Rata & 3,126129 & 169,1219 & $5,37 \%$ & 4058,926 \\
\hline & & & & \\
\hline
\end{tabular}

Berdasarkan Tabel 4. Hasil Perhitungan Susut energi penyulang perunggu dapat kita ketahui bahwa presentase susut daya pada penyulang perunggu gardu induk sutami PT. PLN (Persero) Lampung Januari 2020 memiliki nilai rata rata 5,37\% dan besar-nya susut energi yang terjadi selama satu bulan adalah sebesar $125826,7 \mathrm{kWh}$ dengan nilai rata rata susut energi yaitu 4058,26 kWh perharinya jika dalam bulan bulan berikutnya susut energi yang terjadi adalah sama jika diakumulasikan selama satu tahun susut energi tahunan pada pada penyulang perunggu adalah 1.509.920,4 kWh.

\section{KESIMPULAN DAN SARAN}

\subsection{Kesimpulan}

Berdasarkan hasil perhitungan yang telah dilaksanakan untuk mengetahui besarnya susut energi Penyulang Perunggu PT. PLN (Persero) area Lampung maka dapat disimpulkan. Besarnya susut daya pada saluran distribusi dipengaruhi oleh panjang penghantar, jenis dan diameter penghantar dan juga suhu dari pada kawat penghantar. Besarnya susut energi yang terjadi pada jangka watu satu bulan pada bulan januari 2020 pada penyulang perunggu gardu induk sutami dengan panjang saluran 21,67 KM memiliki nilai susut energi sebesar $123.433,2 \mathrm{kWh}$.

\subsection{Saran}

untuk menekan besarnya susut daya, maka perlu dilakukannya pemeliharaan dan perbaikan pada saluran distribusi beberapa saran yang dapat diberikan diantaranya : 
1. Salah satu cara untuk menekan besarnya susut daya adalah mengganti jenis atau luas penampang pada saluran menjadi lebih besar, agar nilai resistansi yang didapatkan dalam penyaluran tidak terlalu besar.

2. Untuk melakukan perhitungan susut daya dapat menggunakan software ETAP untuk mempermudah dalam melakukan simulasi perhitungan.

\section{UCAPAN TERIMA KASIH}

Dalam Penulisan Penelitian ini penulis mendapatkan bantuan dan dorongan dari berbagai pihak, oleh karena itu penulis ucapkan terimakasih kepada semua pihak tidak dapat penulis sebutkan satu persatu.

\section{DAFTAR PUSTAKA}

[1] Bachtiar, H. (2018). Rugi Rugi daya pada Penghantar Saluran Udara Tegangan Tinggi (SUTT) 150kV Gardu Induk duri kosambi - Gas Insuled Switchgear (GIS) Grogol. Jakarta: Sekolah Tinggi Teknik PLN.

[2] Hanifatullah, Q. A., Martianti, Y. (2018). Evaluasi Susut Daya Penyulang Cendana $20 \mathrm{kV}$ pada Gardu Bungaran denga ETAP 12.6. Jurnal Teknik Elektro ITP, Vol 7, No. $1,79-93$.

[3] Khoiriyah, S. (2018). Analisa susut daya dan energi pada jaringan distribusi di gardu induk bringin penyulang BRG-4 menggunakan software ETAP 12.6. Yogyakarta: Universitas Muhammadiyah Yogyakarta.

[4] Samsurizal, S., Hadinoto, B. (2020). Studi Analisis Dampak Overload Transformator Terhadap Kualitas Daya Di PT. PLN (Persero) UP3 Pondok Gede. KILAT, 9(1), 136 142.

[6] PT. PLN (Persero). (1981). SPLN 41-8 : 1981 Hantaran Alumunium Campuran (AAAC).

[7] PT. PLN (Persero). (1995). SPLN 43-5-4 :1995 Kabel Tanah Inti Tiga Berisolasi XLPE berselubung PE/PVC.

[7] PT. (PLN Persero). (1978). SPLN 11978 Susut Pada Jaringan.

[8] PT. PLN (Persero). (1981). SPLN 41-8 : 1981 Hantaran Alumunium Campuran (AAAC).

[9] PT.PLN (Persero). (1987). SPLN 87:1991 Suhu Tertinggi pada penghantar

[10] PT. PLN (Persero). (1995.) SPLN 43-5-4 :1995 Kabel Tanah Inti Tiga Berisolasi XLPE berselubung PE/PVC.

[11] Standar IEC 60502-2 Kabel pilin berisolasi 